\title{
WPLYW SKLADU MIESZANKI I WYJŚCIOWEGO ZAWILGOCENIA KRUSZYWA LEKKIEGO NA SORPCYJNOŚĆ KAPILARNĄ BETONU KERAMZYTOWEGO
}

\begin{abstract}
W artykule opisano badania kapilarności przeprowadzone na grupie sześciu betonów keramzytowych, wykonanych na bazie tych samych składników. W każdym przypadku użyto tego samego cementu portlandzkiego 42,5 R, wody wodociągowej pitnej oraz kruszywa keramzytowego frakcji $4-8 \mathrm{~mm}$ oraz piasku kwarcowego frakcji $0-2 \mathrm{~mm}$. Poszczególne receptury różniły się po pierwsze stanem wilgotnościowym kruszywa grubego, które wprowadzane było do mieszanki jako kruszywo suche $(\mathrm{S})$, powietrzno-suche $(\mathrm{P})$ oraz w pełni nasycone wodą $(\mathrm{N})$. Po drugie mieszanki różniły się objętościowym udziałem kruszywa lekkiego i zaprawy cementowej. Przyjęto proporcje zaprawa cementowa : kruszywo keramzytowe na poziomie $1: 1$ oraz $3: 2$. W rezultacie badaniom poddano 6 mieszanek umownie oznaczonych jako S 1:1, P 1:1, N 1:1 oraz S 3:2, P 3:2, N 3:2. Wykazano, że betony te charakteryzują się wyraźnie różnym tempem podciągania kapilarnego, a tym samym różnymi wartościami współczynników sorpcji kapilarnej $A$. Najlepszymi parametrami odznaczały się betony wykonane na kruszywie suchym o stosunku zaprawa:kruszywo 1:1. Wykazały one najniższą wartość współczynnika sorpcji wynoszącą $A=0,9 \mathrm{~kg} /\left(\mathrm{m}^{2} \sqrt{ } \mathrm{h}\right)$. Ten rodzaj betonu będzie najefektywniej blokował wnikanie wody w beton i w konsekwencji będzie odznaczał się najwyższą odpornością na działanie substancji korozyjnych wprowadzanych z wodą oraz najwyższą mrozoodpornością. Najgorszymi parametrami charakteryzowały się keramzytobetony o większym udziale objętościowym zaprawy cementowej, tj. o proporcjach zaprawa:kruszywo keramzytowe 3:2. Przy czym w przypadku kruszywa nasyconego wodą $(\mathrm{N})$ i ziarnach wysuszonych na powierzchni $(\mathrm{P})$ uzyskano współczynniki $A$ wyższe odpowiednio $2,5 \div 2,8$ razy w stosunku do receptury S 1:1.
\end{abstract}

Słowa kluczowe: keramzytobeton, kapilarność, współczynnik sorpcji wody, wilgotność kruszywa lekkiego

\footnotetext{
${ }^{1}$ Autor do korespondencji / corresponding author: Halina Garbalińska, Zachodniopomorski Uniwersytet Technologiczny w Szczecinie, Wydział Budownictwa i Architektury, Al. Piastów 50, 70-311 Szczecin, tel. 9144948 29, e-mail: Halina.Garbalińska@zut.edu.pl

${ }^{2}$ Klaudia Narodowska, absolwentka Zachodniopomorskiego Uniwersytetu Technologicznego w Szczecinie, al. Piastów 50, 70-311 Szczecin, 91-449-48-29, nar.klaudia@wp.pl
} 


\section{Wstęp}

Znaczącą rolę w kształtowaniu właściwości zarówno samej mieszanki, jak i dojrzałego kompozytu odgrywa skład recepturowy, jak również podejmowane zabiegi technologiczne, w tym wstępne nawilżenie kruszywa lekkiego.

W ramach pracy [6] przeprowadzono badania, których celem miała być analiza wpływu wyjściowego zawilgocenia kruszywa lekkiego oraz stosunku objętości tego kruszywa do objętości zaprawy w mieszance betonowej na przebieg procesu podciągania kapilarnego, będącego miernikiem późniejszej trwałości materiału eksploatowanego w zmiennych warunkach środowiskowych.

Wysoka podatność kruszywa lekkiego na absorpcję wody z mieszanki betonowej jest jedną z najbardziej niepożądanych cech, a wyeliminowanie jej negatywnego wpływu na urabialność mieszanki betonowej jest stosunkowo trudnym procesem. Zgodnie $\mathrm{z}$ informacjami zawartymi w [2] kruszywo lekkie w stanie suchym jest zdolne do odciągnięcia z $1 \mathrm{~m}^{3}$ mieszanki betonowej $30 \div 90 \mathrm{~kg}$ wody. Równocześnie jednak owa zdolność do absorpcji wpływa na obniżenie współczynnika wodno-cementowego, co powoduje wzmocnienie matrycy cementowej, a absorpcja zaczynu z mieszanki betonowej przyczynia się do doszczelnienia i wzmocnienia struktury ziaren kruszywa lekkiego.

Niestety powszechnie stosowane metody projektowania składu betonów zwykłych nie kwalifikują się do zastosowania w przypadku betonów lekkich, bowiem nie uwzględniają m.in. możliwości wchłaniania wody przez ziarna kruszywa, [3]. Najczęściej stosowaną metodą do określenia składu mieszanki betonów lekkich jest metoda objętościowa [2].

Betony lekkie, jeśli są eksploatowane w kontakcie $\mathrm{z}$ otoczeniem, narażone są na liczne wpływy środowiskowe, m.in. związane $\mathrm{z}$ działaniem wody pochodzącej z różnych źródeł, omówionych np. w [5]. Najbardziej destrukcyjnie działa woda w fazie ciekłej, wprowadzona do wnętrza elementu w wyniku działania sił podciągania kapilarnego. Transport kapilarny dotyczy porowatych materiałów budowlanych, w których woda rozprzestrzenia się, wędrując siecią naczyń włosowatych występujących w obrębie materiałów porowatych. W zależności od specyficznej mikrostruktury poszczególnych materiałów, woda $\mathrm{w}$ różnym tempie i różnym zakresie wprowadzana jest do wnętrza przegrody budowlanej.

\section{Wspólczynnik sorpcji kapilarnej}

Parametrem opisującym ilościowo zjawisko podciągania kapilarnego w porowatym materiale jest współczynnik sorpcji $A$. Metodyka jego pomiaru sposobem tradycyjnym polega na zetknięciu $\mathrm{z}$ lustrem wody jednej z powierzchni badanej próbki, a następnie rejestracji tempa zachodzącego $\mathrm{w}$ niej procesu niestacjonarnego. Oznaczenie wartości omawianego współczynnika sprowadza się w takim wypadku do pomiaru masy wody wchłoniętej przez próbkę w jednostce 
czasu, przy czym rejestracja prowadzona jest często aż do momentu ustabilizowania się masy badanych próbek, [4].

Współczynnik sorpcji wody $A$, zgodnie z normą PN-EN ISO 9346 [7], definiowany jest następującą zależnością:

$$
m_{s}=A \sqrt{ } t
$$

gdzie:

$A$ - współczynnik sorpcji wody, $\left[\mathrm{kg} /\left(\mathrm{m}^{2} \mathrm{~h}^{1 / 2}\right)\right]$,

$m_{s}$ - masa wilgoci zaabsorbowanej $\mathrm{z}$ powierzchni styku $\mathrm{z}$ wodą, podzielona przez pole tej powierzchni, $\left[\mathrm{kg} / \mathrm{m}^{2}\right]$,

$t$ - czas, [h].

Współczynnik $A$ jest interpretowany jako tangens kąta nachylenia liniowego odcinka na wykresie funkcji $\Delta m_{t} / F=\mathrm{f}(\sqrt{ } t)$. Przy czym $\Delta m_{t}$ oznacza przyrost masy badanej próbki po czasie $t$, natomiast $F$ - powierzchnię jej kontaktu z wodą, [4]. Współczynnik sorpcji kapilarnej, który uwarunkowany jest w największym stopniu charakterem struktury porowatości materiału, można zatem wyznaczać za pomocą wzoru, [5]:

$$
A=\frac{\Delta m_{t}}{F \Delta \sqrt{t}}
$$

który zastosowany został w tej postaci w obliczeniach współczynników $A$ odnoszących się do poszczególnych próbek, wykonanych według sześciu przyjętych receptur.

\section{Opis zrealizowanych badań}

Do wykonania betonów lekkich, testowanych w ramach pracy [6], zostało użyte kruszywo keramzytowe o wymiarach ziaren od 4 do $8 \mathrm{~mm}$, które wprowadzono do mieszanki $w$ trzech różnych stanach nawilżenia, jako: nasycone $(\mathrm{N})$, suche (S) i powierzchniowo-suche $(\mathrm{P})$. Dodatkowo testowano dwa warianty objętościowych relacji składników, przyjmując stosunek objętości zaprawy do objętości kruszywa równy 1:1 oraz 3:2. Wykorzystano w każdym przypadku ten sam cement portlandzki $42,5 \mathrm{R}$, ten sam piasek kwarcowy o granulacji $0 \div 2 \mathrm{~mm}$ oraz wodę wodociągową pitną.

$\mathrm{W}$ celu uzyskania miarodajnych i jednoznacznych wyników podjęto się wykonania wstępnych badań poszczególnych surowców użytych do wytworzenia wszystkich mieszanek.

Aby uzyskać dane pozwalające określić czas suszenia i nasączania kruszywa lekkiego, przeprowadzono analizę właściwości keramzytu. Badanie wykonywane przy użyciu piknometru wykazało, iż keramzyt charakteryzuje się gęstością ziaren na poziomie $669 \mathrm{~kg} / \mathrm{m}^{3}$. Jego gęstość nasypowa w stanie luźnym 
wyniosła $376 \mathrm{~kg} / \mathrm{m}^{3}$, natomiast w postaci zagęszczonej $405 \mathrm{~kg} / \mathrm{m}^{3}$. Znaczna jamistość omawianego kruszywa lekkiego, około 52\%, wskazywała na obecność licznych wolnych przestrzeni pomiędzy poszczególnymi ziarnami. Zważywszy na niezwykle niską wilgotność keramzytu w stanie naturalnym, zdecydowano się na jej nieuwzględnianie $\mathrm{w}$ trakcie przygotowywania mieszanek betonowych.

Przeprowadzono natomiast systematyczne badania nasiąkliwości, które pozwoliły uzyskać informacje o zmianach tej właściwości w trakcie 48-godzinnego namaczania kruszywa. Wyznaczone w charakterystycznych punktach czasowych nasiąkliwości wynosiły: po 5 minutach: $W_{s}=18,29 \%$; po 60 minutach $W_{60}=20,45 \%$; po 24 godzinach $W_{24}=26,15 \%$; po 48 godzinach $W_{F}=27,56 \%$.

Podjęto się także przebadania kinetyki procesu wysychania, aby uzyskać informacje na temat zwiększania się głębokości strefy suchej ziaren keramzytu wraz z upływem czasu. Dane te wykorzystano w [6] przy dobieraniu poszczególnych stanów wilgotnościowych kruszywa grubego.

Dodatkowo określono także właściwości zastosowanego do produkcji mieszanki betonowej kruszywa drobnego oraz cementu portlandzkiego. Stosując normowy zestaw sit badawczych określono skład granulometryczny piasku kwarcowego. Zbadano również wilgotność kruszywa drobnego w stanie naturalnym, która wyniosła 3,64\%. Przeprowadzone badania cementu portlandzkiego 42,5R pozwoliły potwierdzić zgodność jego cech z wymaganiami normowymi. $\mathrm{W}$ badaniach wytrzymałości na ściskanie przeprowadzonych po upływie $28 \mathrm{dni}$ dojrzewania uzyskano wartość średnią rzędu $56 \mathrm{MPa}$. Określony doświadczalnie na dwóch próbach początek czasu wiązania wyniósł $215 \div 220 \mathrm{~min}$, natomiast koniec wiązania $240 \div 270 \mathrm{~min}$.

Ustalenie składu mieszanki betonowej rozpoczęto od określenia objętości nasypowej całkowicie nasączonego i zagęszczonego kruszywa keramzytowego. Oznaczenie przeprowadzono na trzech próbkach kruszywa, używając do tego celu odpowiedniego cylindra pomiarowego. W kolejnym etapie wyznaczono ilości wody i piasku niezbędne do wytworzenia zaprawy, dla wstępnie przyjętej masy cementu równej $400 \mathrm{~g}$. W trakcie przeprowadzania obliczeń uwzględniono również korektę ilości wody i piasku z uwagi na wilgotność naturalną kruszywa.

Do analizy przebiegu podciągania kapilarnego, a w szczególności wyznaczenia współczynników sorpcji kapilarnej $A$, wykorzystano łącznie 24 próbki prostopadłościenne o wymiarach $4 \times 4 \times 16 \mathrm{~cm}$. Zastosowano $\mathrm{w}$ badaniach po 12 próbek dla dwóch przyjętych stosunków ilości zaprawy do ilości kruszywa keramzytowego, tj. 1:1 oraz 3:2, przy czym dla każdego z tych stosunków wykorzystano po 4 próbki z kruszywem $\mathrm{w}$ trzech stanach nasycenia: suchym, powierzchniowo-suchym i nasyconym. W celu określenia sorpcyjności każdego $\mathrm{z}$ testowanych betonów zastosowano metodę grawimetryczną, $\mathrm{w}$ której próbki poddawane były działaniu wody podciąganej przeciwnie do kierunku działania siły grawitacji. Wszystkie 24 prostopadłościenne próbki sześciu rodzajów betonu lekkiego kruszywowego zostały umieszczone w układzie pionowym w kuwe- 
tach wyłożonych stabilizującymi podkładkami, a ich dolne powierzchnie zostały zalane destylowaną wodą na wysokość ok. $0,2 \mathrm{~cm}$.

Rejestrację wzrastającej masy próbek, poddanych procesowi podciągania kapilarnego, prowadzono przez okres 12 dni, ważąc je w ustalonych odstępach czasu, dostosowanych do tempa przebiegu procesu. Ważenie próbek przeprowadzano z wykorzystaniem wagi laboratoryjnej o dokładności $0,01 \mathrm{~g}$, na którą beleczki trafiały po dokładnym osączeniu z zewnętrznego zawilgocenia.

\section{Wyniki uzyskane w badaniach kapilarności}

Przeprowadzone pomiary pozwoliły na graficzne odwzorowanie analizowanych zależności, tj. zmieniającej się masy próbek odniesionej do pola ich powierzchni mających kontakt $\mathrm{z}$ wodą, w funkcji pierwiastka $\mathrm{z}$ czasu. Zbiorcze wykresy wypadkowych przebiegów zestawiono na rys. 1.

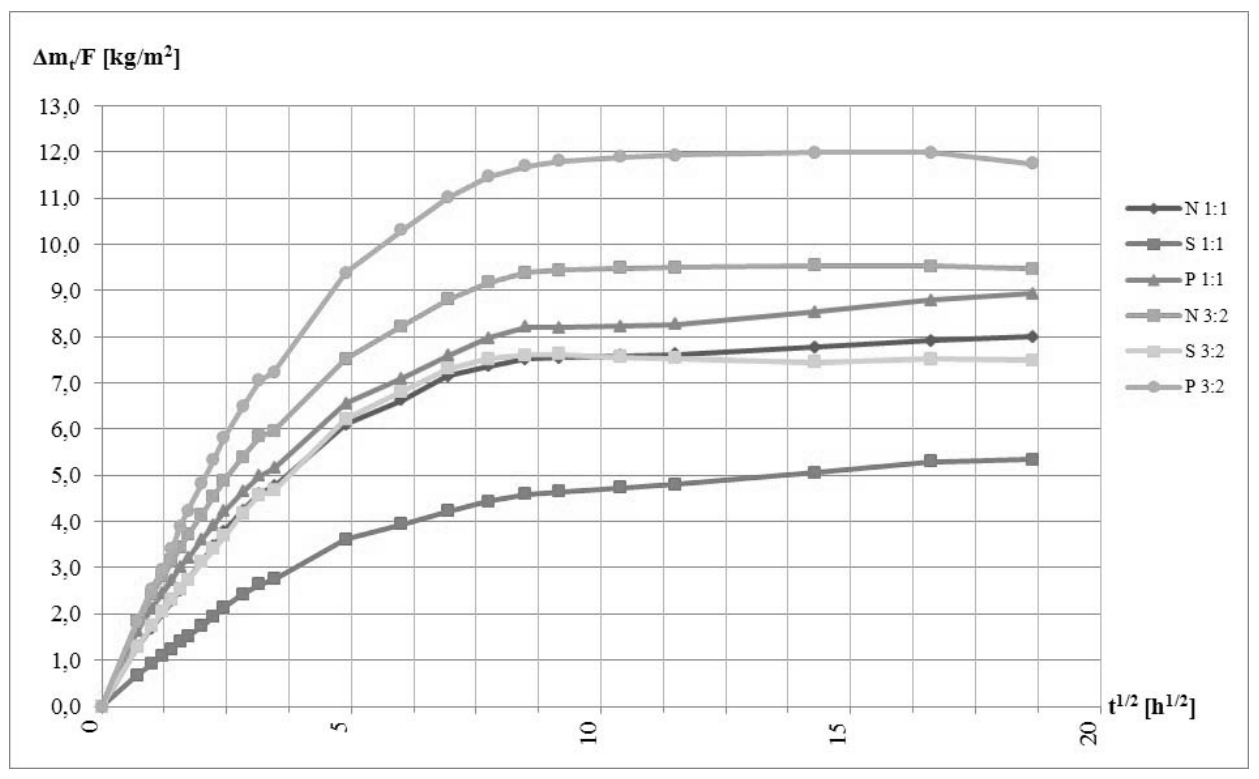

Rys. 1. Zestawienie uśrednionych zależności $\Delta m_{t} / F=f(\sqrt{ } t)$ dla sześciu betonów lekkich na kruszywie keramzytowym w trzech różnych stanach zawilgocenia, przy dwóch odmiennych stosunkach objętościowych zaprawy do kruszywa grubego

Fig. 1. Statement of the average relationship $\Delta m_{t} / F=f(\sqrt{ } t)$ for six lightweight concretes based on expanded clay aggregates, for three different moisture states, and two different volume ratios of mortar and coarse aggregate

Wyznaczenie współczynników sorpcji kapilarnej $A$ sprowadzało się do przyjęcia określonej liczby punktów pomiarowym we wczesnym etapie badania podciągania kapilarnego, które lokowały się w zakresie liniowej zależności 
zmieniającej się masy próbek $\mathrm{w}$ odniesieniu do powierzchni ssania $\mathrm{w}$ funkcji pierwiastka z czasu. Uzyskane wypadkowe wartości współczynników $A$ zobrazowano w postaci wykresu kolumnowego na rysunku 2.

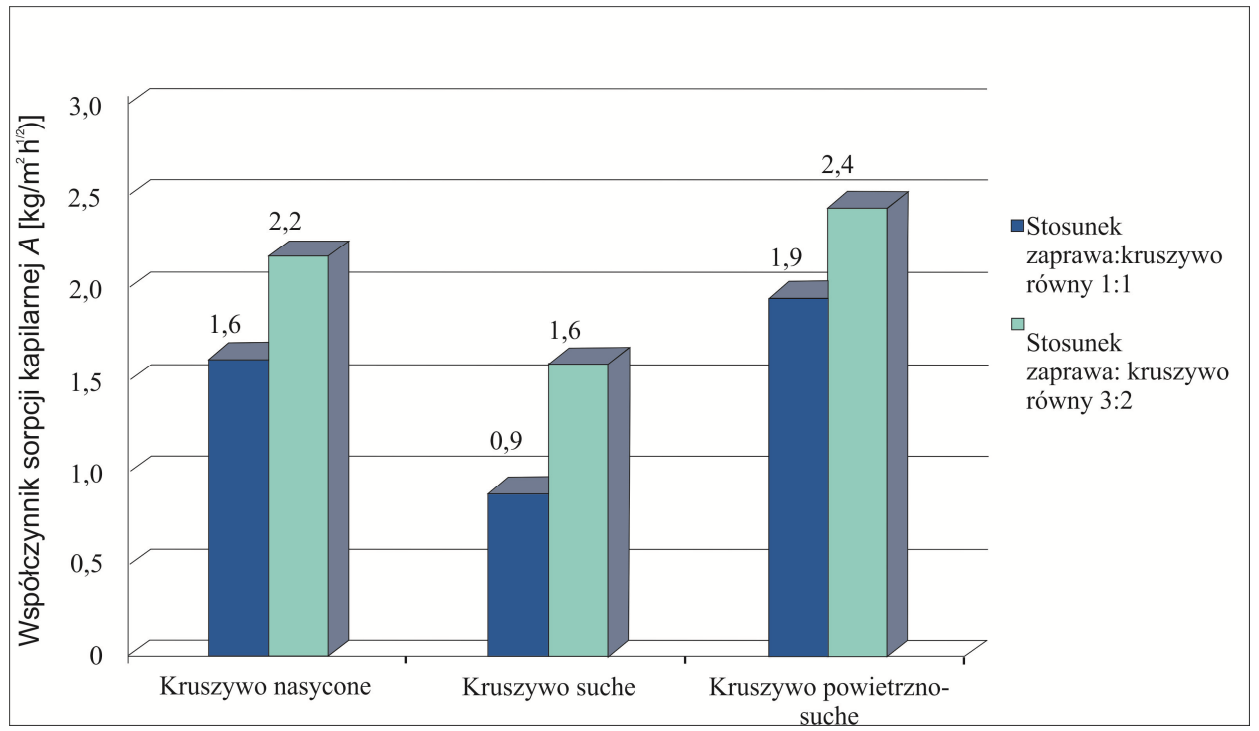

Rys. 2. Średnie wartości współczynnika sorpcji $A$ dla poszczególnych kombinacji stanu zawilgocenia kruszywa i stosunku objętości zaprawy do objętości kruszywa grubego

Fig. 2. Average values of sorption coefficient $A$ for particular moisture states of aggregate and volume ratio of mortar and coarse aggregate

\section{Podsumowanie}

Analiza uzyskanych uśrednionych wykresów $\Delta m_{t} / F=f(\sqrt{ } t)$ sześciu betonów lekkich wykonanych na bazie kruszywa keramzytowego wykazała, iż w zależności od stanu zawilgocenia kruszywa, a także przyjętego stosunku objętości zaprawy do objętości kruszywa grubego, uzyskuje się zdecydowanie różne tempo podciągania kapilarnego w poszczególnych kompozytach wykonanych na bazie tych samych składników.

Wykazano, że pierwszy z wymienionych powyżej czynników, a więc ilość wstępnej wilgoci w kruszywie lekkim, przyczynia się do wystąpienia znacznych różnic w szybkości pochłaniania wody, szczególnie w trakcie pierwszych 12 godzin od zainicjowania kontaktu powierzchni próbek z cieczą. Przy czym beton, do produkcji którego wykorzystano keramzyt w stanie suchym, charakteryzuje się najmniejszą dynamiką omawianego procesu, stąd średni współczynnik sorpcji $A$ w przypadku jego próbek wyniósł zaledwie $0,9 \mathrm{~kg} /\left(\mathrm{m}^{2} \mathrm{~h}^{1 / 2}\right)$ przy stosunku zaprawy do kruszywa równym 1:1 oraz $1,6 \mathrm{~kg} /\left(\mathrm{m}^{2} \mathrm{~h}^{1 / 2}\right)$ przy stosunku 3:2. 
Najmniej korzystny z uwagi na możliwości blokowania kapilarnego wnikania wody okazał się beton wykonywany na kruszywie w stanie powietrznosuchym, wykazujący się najwyższymi współczynnikami sorpcji, wynoszącymi $1,9 \mathrm{~kg} /\left(\mathrm{m}^{2} \mathrm{~h}^{1 / 2}\right)$ przy stosunku zaprawy do kruszywa $1: 1$ oraz $2,4 \mathrm{~kg} /\left(\mathrm{m}^{2} \mathrm{~h}^{1 / 2}\right)$ przy stosunku 3:2.

Przeprowadzone badania dowiodły także znacznego zróżnicowania uzyskiwanych równowagowych akumulacyjnościach kapilarnych, przy czym najniższymi wartościami odznaczały się kompozyty wykonane na bazie kruszywa suchego.

Zebrane wyniki wskazują ponadto na występowanie jednoznacznej tendencji związanej z różnym objętościowym udziałem poszczególnych składników w każdym z trzech testowanych stanów wilgotnościowych kruszywa wyraźnie większą dynamikę procesu podciągania wykazywały próbki betonów wykonanych przy założeniu stosunku zaprawy do kruszywa keramzytowego 3:2. $\mathrm{W}$ efekcie w betonach tego rodzaju intensywniej będzie wprowadzana woda do ich wnętrza, a wraz z nią ewentualne substancje korozyjne. Skutkować to będzie obniżeniem trwałości i mrozoodporności elementów budowlanych wykonanych według tej technologii.

Przeprowadzone badania testujące pozwalają stwierdzić, iż niezależnie od zastosowanego stosunku składników, najskuteczniej blokuje podciąganie kapilarne beton wykonany na bazie keramzytu pozbawionego wilgoci. Dodatkowo intensywność procesu podciągania kapilarnego można ograniczyć zmniejszając udział objętościowy zaprawy w stosunku do kruszywa grubego. Maleje w tym przypadku znacząco zarówno tempo procesu wyrażone w wartości współczynnika $A$ (o około 45\%), jak i chłonność kapilarna (o około 30\%).

\section{Literatura}

[1] Alsabry A.: Transport wilgoci w przegrodach budowlanych z materiałów kapilarnoporowatych, Uniwersytet Zielonogórski, Zielona Góra 2011.

[2] Domagała L.: Konstrukcyjne lekkie betony kruszywowe, Politechnika Krakowska, Kraków 2014.

[3] Ganter E., Chojczak W.: Materiały budowlane. Spoiwa, kruszywa, zaprawy, betony. Ćwiczenia laboratoryjne, Oficyna Wydawnicza Politechniki Warszawskiej, Warszawa 2013.

[4] Garbalińska H.: Izotermiczne współczynniki transportu wilgoci porowatego materiału budowlanego, Wydawnictwo Uczelniane Politechniki Szczecińskiej, Szczecin 2002.

[5] Klemm P. i in.: Budownictwo ogólne. Tom 2. Fizyka budowli, Arkady, Warszawa 2005.

[6] Narodowska K.: Badania i analiza wybranych właściwości betonów lekkich wykonanych na kruszywie keramzytowym. Praca dyplomowa inżynierska realizowana pod kierunkiem H. Garbalińskiej, Zachodniopomorski Uniwersytet Technologiczny w Szczecinie, czerwiec 2015.

[7] PN-EN ISO 9346 (2009): Cieplno-wilgotnościowe właściwości użytkowe budynków i materiałów budowlanych. Wielkości fizyczne dotyczące przenoszenia masy. Słownik. 


\title{
INFLUENCE OF MIX COMPOSITION AND INITIAL MOISTNESS OF LIGHTWEIGHT AGGREGATE ON CAPILLARY SORPTION OF EXPANDED CLAY AGGREGATE CONCRETE
}

\begin{abstract}
S u m m a r y
This paper presents the results of capillary porosity tests carried out using six expanded clay aggregate concretes, made from the same ingredients. Each aggregate was manufactured with the same type of Portland cement $42.5 \mathrm{R}$, potable mains water, expanded clay aggregate $(4-8 \mathrm{~mm})$, and quartz sand $(0-2 \mathrm{~mm})$. The effect of coarse aggregate humidity on the mixture was examined using dry $(\mathrm{S})$, air-dry $(\mathrm{P})$ and fully saturated $(\mathrm{N})$ aggregates. Additionally, the mixtures had different volume ratios of lightweight aggregate and cement mortar. Ratios of 1:1 and 3:2 of cement mortar and expanded clay aggregate were used. Consequently, tests were carried out using 6 mixture types labelled S 1:1, P 1:1, N 1:1 and S 3:2, P 3:2, N 3:2. The results confirmed that these concretes had significantly different rates of capillarity and water absorption coefficients due to capillarity. The best results were obtained from concretes made using the dry aggregate with a 1:1 ratio of mortar and aggregate. This concrete had the lowest coefficient of $A=0.882 \mathrm{~kg} /\left(\mathrm{m}^{2} \sqrt{\mathrm{h}}\right)$. This type of concrete should most efficiently prevent water absorption and, as a consequence, ensure the highest resistance to corrosive substances carried by water, as well as the highest freeze-thaw resistance. The least favourable were expanded clay aggregate concretes with a large volume of mortar, namely a 3:2 ratio of cement mortar and expanded clay aggregate. For aggregates saturated with water $(\mathrm{N})$ and aggregate particles dried on the surface $(\mathrm{P})$, the A coefficient was 2.5 and 2.8 times higher with respect to the S 3:2 mixture.
\end{abstract}

Keywords: lightweight concrete, capillarity, water sorption coefficient, moisture of lightweight aggregate

Przestano do redakcji: $25.05 .2016 r$.

Przyjęto do druku: 15.12.2017 r. 